Aspectos del montaje en la poética de Val del Omar

Eduardo A. Russo

Arkadin (N. ${ }^{\circ}$ 9), e018, 2020. ISSN 2525-085X

https://doi.org/10.24215/2525085Xe018

http://papelcosido.fba.unlp.edu.ar/ojs/index.php/arkadin

Facultad de Artes. Universidad Nacional de La Plata

La Plata. Buenos Aires. Argentina

\title{
ASPECTOS DEL MONTAJE EN LA POETICA DE VAL DEL OMAR
}

\section{Aspects of Montage in the Poetics of Val del Omar}

EDUARDO A. RUSSOI earusso@fba.unlp.edu.ar

Instituto de Investigación en Producción y Enseñanza del Arte Argentino y Latinoamericano. Facultad de Artes. Universidad Nacional de La Plata. Argentina

Recibido: 6/3/2020 | Aceptado: 22/6/2020

\section{RESUMEN}

La múltiple producción del cineasta, fotógrafo, poeta e inventor José Val del Omar permite pensar una noción del montaje desplegada bajo el signo de la intermedialidad. Al recorrer medio siglo de su práctica artística en diversos formatos, su actividad como inventor de artefactos audiovisuales, más su producción como escritor, se revela una común preocupación por el montaje ejercido por diversos medios, entendido como elemento clave de una verdadera misión para el cine: la transformación del espectador. Este artículo recorre, mediante el hilo conductor del montaje en sus dimensiones poéticas, estéticas y técnicas, algunas operaciones fundamentales de su obra realizativa y su pensamiento.

\section{PALABRAS CLAVE}

Montaje; experimental; vanguardia; documental; estética

\section{ABSTRACT}

The multiple output of the filmmaker, photographer, poet and inventor José Val del Omar allow us to think a concept of montage unfolded under the sign of intermediality. Addressing half a century of his work in various media and apparatus, his activity as an inventor of audiovisual artifacts, plus his productions as a writer, Val del Omar reveals a common concern for montage by various media, understood as a key element of a mission for cinema: the transformation of the spectator. This article addresses, through the common thread of montage in his poetics, asthetics and technical dimensions, some fundamental operations of his filmmaking and his thought.

\section{KEYWORDS}

Montage; experimental; avant garde; documentary; aesthetics

1 Este artículo forma parte de la investigación SECyT 2018-2021: Transiciones y tránsitos en el cine contemporáneo. Agradecemos a Lola Hinojosa, del Museo Nacional Centro de Arte Reina Sofía (MNCARS), por el acceso a los fondos Val del Omar allí alojados, y a Carla Giachello por la asistencia en su consulta. A Gonzalo Sáenz de Buruaga agradecemos el temprano apoyo y estímulo a nuestras incursiones valdelomarianas, y a Gonzalo de Lucas la visualización de los materiales de Val del Omar producidos en el PLAT, exhibidos en el Ciclo Xcentric del Centro de Cultura Contemporánea de Barcelona (CCCB). 


\section{EL MONTAJE EN EL CINEMISTA}

A casi cuatro décadas de su desaparición, el fotógrafo, escritor, cineasta e inventor granadino José Val del Omar (1904-1982) es aún una figura que excede categorías y todavía por revelar en su justa dimensión. Su reconocimiento póstumo creció en forma paulatina. Hacia la década del noventa una limitada pero ferviente comunidad de seguidores prolongaba su legado, en consonancia con círculos cinéfilos y con la entonces muy activa cultura del videoarte. En ese entonces, su producción circuló casi como contraseña entre iniciados, gracias a algunas muestras intermitentes y codiciados videocasetes, que pese a su escasez trascendieron las fronteras nacionales. Algunas relevantes figuras, como las de Víctor Erice, desde el cine; Eugeni Bonet, entre el cine experimental y el videoarte; Román Gubern, desde la teoría e historia cinematográfica, o Salvador Pániker, desde la filosofía, entre otros, llamaron la atención sobre una obra que había sido realizada en progresivo aislamiento y era amenazada por el olvido.

Un giro se produjo luego del inicio del nuevo siglo, gracias al impulso anterior y a la difusión digital y la expansión del cine hacia los espacios del museo y la galería. La obra de Val del Omar comenzó a ser reconocida, extendiendo su presencia y proyectándose internacionalmente de un modo más sistemático. Esta recuperación y puesta en valor hoy no atañe solo sus films, sino también a buena parte de la panoplia de artefactos técnicos que había ideado en busca de una verdadera reinvención del cine, restaurados o reconstruidos con el fin de demostrar las experiencias que él perseguía, conservados desde 2011 por donación de sus familiares en el Museo Nacional Centro de Arte Reina Sofía (MNCARS). Es posible considerar, de ese modo, que el reconocimiento de Val del Omar por una creciente comunidad global de seguidores es un fenómeno fundamentalmente localizado en el siglo XXI.

Gracias a los trabajos de investigación y de curaduría emprendidos por un tenaz núcleo de entusiastas valdelomarianos, entre los que desde el comienzo de la difusión de su obra se destacaron su yerno Gonzalo Sáenz de Buruaga y su hija, María José Val del Omar, la influencia del granadino no ha cesado de crecer. El impacto abarca los territorios del cine, el video y el arte digital, las artes visuales y la música, entre otras formas artísticas, mientras los estudios sobre su obra y las muestras se multiplican. Nos proponemos aquí examinar en la teoría y la práctica de Val del Omar la presencia transversal de distintas instancias y concepciones del montaje que, por cierto, hacen a su lenguaje poético y han quedado plasmadas en sus películas. Pero también el montaje, en un sentido más abarcativo, es un fundamental principio articulador de sus producciones, fueran estas plasmadas en fotografías, en film, en video, en piezas gráficas o en multimediales. Incluso participa de sus escritos, entre los que destacan textos técnicos, teóricos y una breve pero fulgurante obra poética (Val del Omar, 2010, 2012). También operaba en sus invenciones tecnológicas, como montaje de orden maquínico, que hasta intentaba delinear cierta utopía industrial en el plano de la creación audiovisual.

Val del Omar se consideraba a sí mismo no un cineasta sino un cinemista. Con esa singular expresión unía su oficio de cineasta con la recóndita profesión del alquimista. Esta imagen de un practicante del cine en cuanto alquimia es sin duda poderosa. Convoca un trabajo de búsqueda incansable, animado por un propósito donde materia y espíritu forman una sola empresa. Imágenes en transformación y proclives a la trasmutación, poniendo en juego otra metamorfosis más elevada: la de aquel sujeto que lleva a cabo la labor alquímica. Elevado desde del poder propio de la imagen, el trabajo del cinemista se detenía en ese culto a la magia de la imagen que el autor compartió con la vanguardia poética francesa, en un encuentro temprano que Nicole Brenez (2010) destacó especialmente al abordar su obra. 


\section{VANGUARDIA, MAQUINISMO Y MONTAJE}

En 1921, durante una estancia en París, José Val del Omar conoció las búsquedas de la entonces floreciente vanguardia poética francesa. No ha quedado registro exacto de qué experiencias o piezas particulares lo impactaron, pero sin duda ese contacto dejó marcas en su propia producción. Lo que encontró el joven poeta y potencial inventor fue ni más ni menos que una común creencia en un cine que pugnaba por cobrar una forma que aún debía ser inventada. El hechizo y una mística de la imagen celebrada como fotogenia, cara a los vanguardistas franceses, fue evidente en su discurso temprano. Pero en ese encuentro también aguardaba una refinada concepción del montaje, traducida en el culto a la sobreimpresión de imágenes y a la exploración de sus posibilidades rítmicas. Destaca Brenez (2010):

\footnotetext{
No se trata de una cuestión de influencia, sino más bien de una posición común frente al cinematógrafo [...]. Se trata de la conciencia compartida de que la estandarización industrial reduce a mínimos las posibilidades del cine, y de que, si se quieren mantener unos ideales estéticos ambiciosos, hay que inventar instrumentos dignos de lo que para ellos parece ser una misión. Pero donde otros inventan una cámara, un filtro o un software, Abel Gance, y sobre todo José Val del Omar, se plantean la totalidad del dispositivo: pantalla, cámara, objetivo, sonido, película, proyector, luces, relación con el espectador... y todo ello a fin de emplear al máximo el poder evocador de las imágenes (p. 49).
}

La cinegrafía, esa voluntad de inscribir en pantalla la poesía de la imagen que había sido impulsada por los vanguardistas franceses, por otra parte, se convertiría en parte el mismo vocabulario valdelomariano. Val del Omar fue cercano a Marcel L'Herbier en su tecnofilia, aunque no la convirtió, como lo hizo el teórico y cineasta francés, en una iconografía reconocible dentro de sus films. En lugar de ello, como en Abel Gance, la tecnofilia será un motor de sus invenciones para renovar la tecnología y un espectáculo cinematográfico en el que cifraba las más altas expectativas. Entre 1931 y 1935 Val del Omar formó parte de las célebres Misiones Pedagógicas de la República Española como fotógrafo y proyeccionista. Aquel emprendimiento oficial liderado por Manuel Bartolomé Cossio aunaba pedagogía popular y utopía: la de integrar a la nación, mediante el arte y la cultura, a los sectores rurales más postergados. De esa época se conservan fotografías y solo un puñado de cortos documentales que Val del Omar realizó en forma independiente, donde también puede advertirse que había asimilado las lecciones de las vanguardias soviéticas (Val del Omar, 1934).

Desde sus primeros films, la pasión tecnológica se aunó en Val del Omar con una concepción del montaje que exploraba la vida de las imágenes. No se trataba, por tanto, de una cuestión de maquinismo, sino de una emulación de la vida orgánica. En uno de sus más conocidos textos tempranos, al desarrollar una idea que sería crucial en toda su trayectoria hasta el presente, Jean-Luc Godard (1956) precisaba que lo que el montaje aportaba al cine no era otra cosa que un latido. Décadas más tarde, resumiendo una larga trayectoria como montajista, Albert Jurgenson (1995) argumentaba a lo largo de todo un volumen que resumía sus experiencias que lo propio del montaje era aportarle a una película su respiración. Ambas concepciones que remiten a una vida en las imágenes resuenan en los escritos que Val del Omar produce a la par de su obra cinematográfica. Allí se evidencia el intento de elaborar una curiosa síntesis entre reflexión ontológica, estética audiovisual y teoría del espectador cinematográfico. № hay apartados especiales sobre el montaje, sino que tal preocupación quedó más bien plasmada en sus abundantes notas técnicas, elaboradas hasta la obsesión, como ocurrirá en el largo e inacabado proceso de edición de Acariño Galaico (1961-1995). En sus textos, el cineasta suele verse a sí mismo como un místico de la imagen, un ferviente acólito de una misión cinematográfica cuyo objetivo último radica en la transformación del espectador mediante un tipo particular de percepción, intelección y emoción de imágenes vivientes. Pero más allá de lo explícito en los escritos, en su práctica como realizador, pedagogo e inventor, actuó en Val del Omar una idea multidimensional de diversas operaciones que evidencian que el cinemista también contenía, sin duda, un apenas disimulado y excepcional cultor 
del montaje. Ese que incorporaba a su lenguaje cinematográfico, por cierto, pero también el montaje maquínico relativo a la invención tecnológica que hacía posible su exploración audiovisual expandida, el literario que operaba en su escritura y el plástico propio de sus collages.

\section{EL MONTAJE EN LA POESÍA DE LA IMAGEN}

En tiempos de la difusión de Aguaespejo granadino (1953-1955) y Fuego en Castilla (1958-1960), Manuel Villegas López [1962] (2015) destacó, luego de pasar revista las indagaciones de Val del Omar sobre la imagen y el sonido, la relevancia otorgada al montaje en su poética:

Para ello, Val del Omar ha utilizado la técnica, que conoce perfectamente, y la ha sabido manejar para llegar a la expresión estética. El logro de esa transmutación es extraordinario. Pero donde el realizador da toda la medida de su creación es en el montaje. Y aquí estalla su libertad total, su gran apertura hacia el horizonte. Sin nada que lo obligue en la apariencia de las cosas, combina sus imágenes guiado por el sentido profundo de lo que tiene ante sus pupilas y ante la mirada superreal de la cámara, su nuevo ojo (p. 156).

Pocos años más tarde, Carlos Fernández Cuenca [1965] (2015) realizaba un balance de la recepción crítica del cineasta, en el que se resaltaban sus hallazgos de montaje. Por lo común, en la brevedad de las reseñas se señalaba un montaje que sobresalía por su potencial poético, sin ahondar en precisiones, o a lo sumo cotejándolo con el de otros autores ligados a la vanguardia histórica. En años más recientes, Thomas Beard (2010) ha relacionado al montaje de Val del Omar con ciertas operaciones llevadas a cabo por artistas norteamericanos como Joseph Cornell o Kenneth Anger, y contraponiéndolas con la de su connacional Luis Buñuel. Por su parte, Brenez (2010) enfatizó la conexión con Gance, a lo cual podríamos agregar una parcial cercanía con Dziga Vertov. Sin desestimar las notables diferencias entre el granadino y el cineasta soviético, cabe resaltar que ambos comparten una común preocupación por el montaje sonoro, tan importante como el visual para ambos. Es preciso recordar que Aguaespejo granadino fue también oportunidad para la presentación de la tecnología visual bautizada por Val del Omar como Tactilvisión, y de su sistema sonoro presentado como Diafonía, que proponía como alternativa al sonido estéreo en auge durante los años cincuenta [Figura 1].

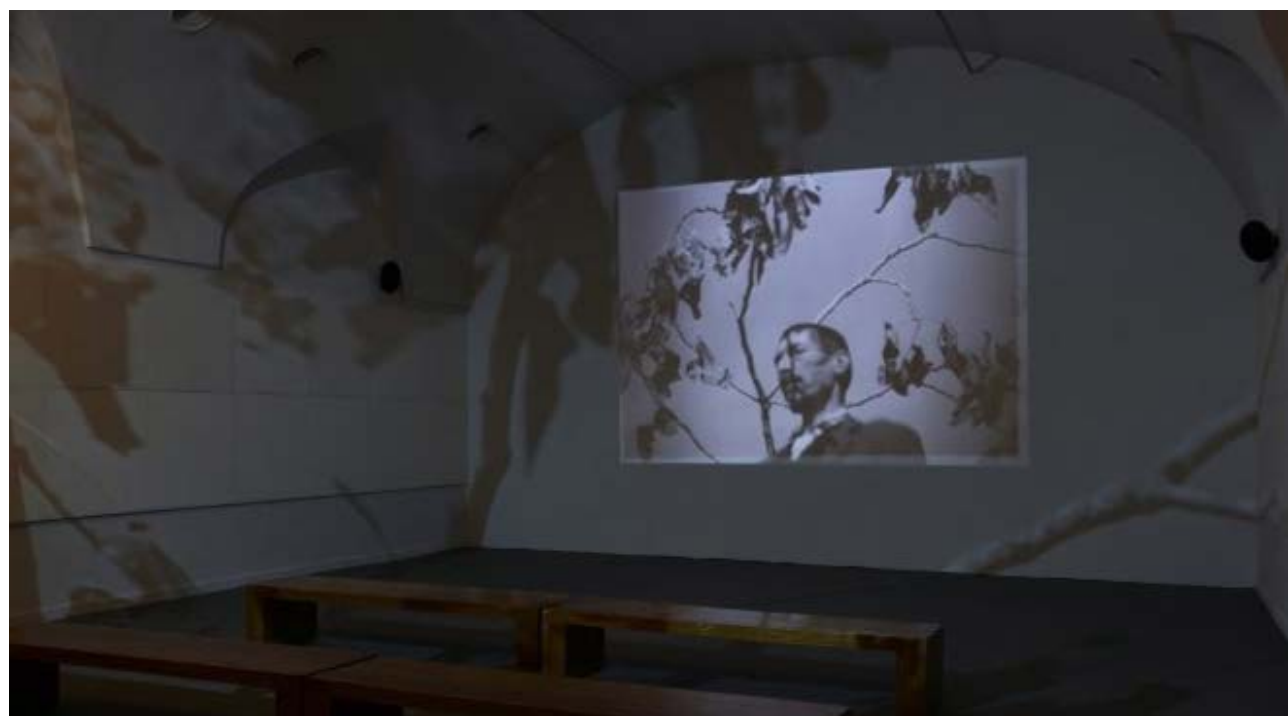

Figura 1. Aguaespejo granadino (1953-1955), de José Val del Omar, proyectada con desbordamiento apanorámico de la imagen 
Entre los trabajos que se extienden en un análisis del montaje en Val del Omar destaca un reciente artículo que Gonzalo de Lucas e Iván Pintor Iranzo (2017) dedican a la poética Aguaespejo granadino. En ese estudio, los autores resaltan cómo las operaciones de yuxtaposición de imagen, el juego con las adyacencias y la rima entre ellas permiten desarrollar esa visión táctil que el autor impulsaba, con tanta eficacia como el trabajo interno dentro de cada plano o los desarrollos tecnológicos propuestos en su registro o proyección, como el desbordamiento apanorámico de la imagen, que expandía lo proyectado más allá de la pantalla, en las paredes de la sala (De Lucas \& Pintor Iranzo, 2017).

Por su parte, al considerar la obra de Val del Omar en conjunto, Eugeni Bonet (2016), uno de los artistas investigadores que más extensamente se ha abocado al estudio de su obra, puntualiza:

[Val del Omar] Concebía sus imágenes como ideogramas y pneumas. Fluyendo en remolinos o según la nueva sintaxis de los intervalos para el drama eléctrico. La noción de intervalo, por cierto, halla un eco anterior en los escritos teóricos de Dziga Vertov, aunque creo improbable que Val del Omar la adoptara por influjo del creador del Cine-0jo, y en definitiva la ha empleado con relación a lo que otras veces llamó dialécticas, encuentros, choques o síntesis de contrarios: la oscuridad y la transparencia, el silencio y el ruido, lo enfocado y lo desenfocado, la vida y su simulacro, lo centrípeto y lo centrífugo, positivo y negativo, infrarrojos y ultravioletas, sístole y diástole, plenitud y vacío, nacer y morir, ternura y violencia y así sucesivamente (p. 94).

El montaje como tensión continua, evocando la respiración o el latido, haciendo vivir a sus films. Esta experiencia podía ser extenuante. En Acariño galaico [Figura 2] Val del Omar trabajó más de dos décadas, y la tarea fue interrumpida por su muerte. Una década luego de su desaparición, a Javier Codesal, uno de los más conspicuos representantes del video arte español durante los años noventa, la Filmoteca de Andalucía le encomendó la elaboración de un montaje para el film inacabado. Era algo más que una tarea de montaje convencional: implicó la reconstrucción y el acabado de un film que sobrevivía en fragmentos, tras haber vivido sucesivas versiones, todas provisorias e insatisfactorias para su autor. El trabajo de Codesal se extendió de 1993 a 1996, pero a su término, el Tríptico elemental de España pudo juzgarse completo. La crónica de ese proceso revela hasta qué punto para Val del Omar la forma advenía en el montaje (Codesal, 2015).

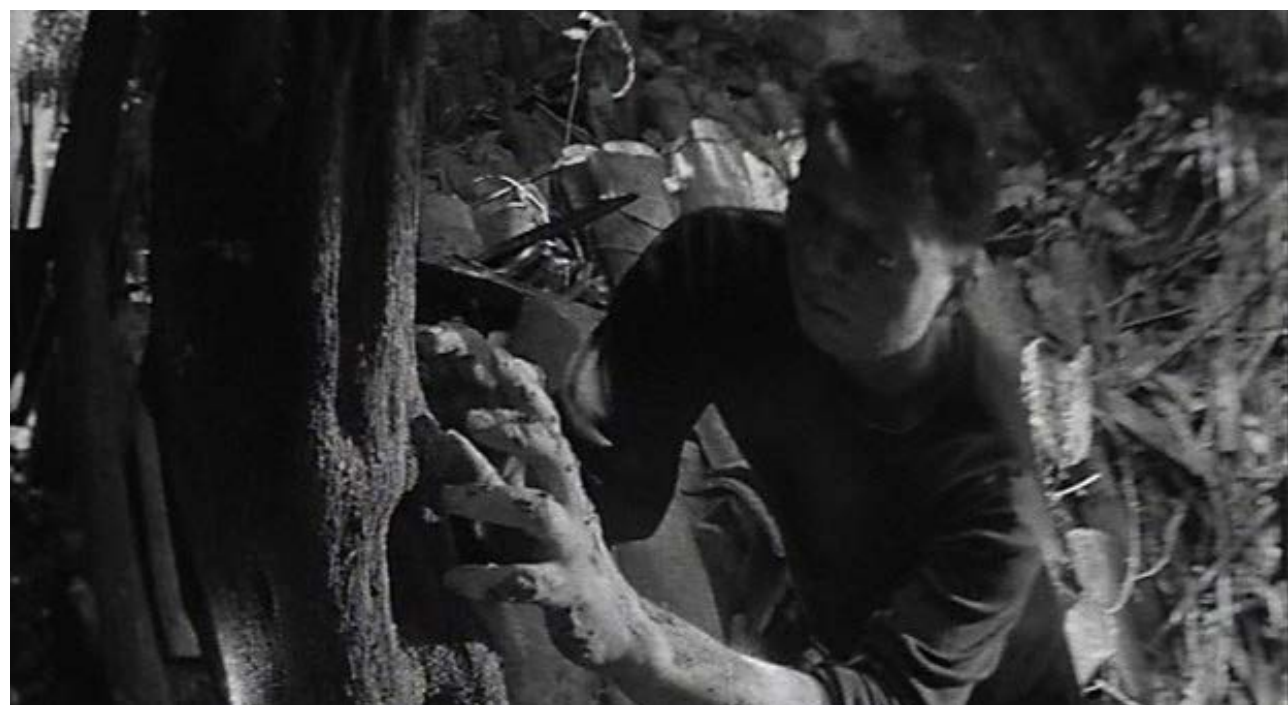




\section{COLLAGE, MONTAJE Y PENSAMIENTO}

A pesar de que once collages de Val del Omar hoy reposan en los depósitos del MNCARS entre otras obras de arte, no son precisamente creación artística sino obra de pensamiento. Compuestos sobre humilde cartón, muestran una yuxtaposición de recortes provenientes de revistas en color con fragmentos de textos mecanografiados y frecuentemente intervenidos por subrayados o anotaciones manuscritas. A veces se inclinan a la predominancia del escrito, en otras oportunidades, una o varias imágenes recortadas dominan el conjunto [Figura 3]. Es difícil, al examinarlos, no percibir el influjo que algunas publicaciones de Marshall McLuhan durante la segunda mitad de los años sesenta, especialmente sus célebres antilibros fundados en la integración entre textos e imágenes, tuvieron en el cineasta. Palabra e imagen son montados aquí mediante su contraste o su potenciación mutua. Lo que se advierte ante los collages de Val del Omar es el intento de proseguir, en condiciones materiales de lo más limitativas, una exploración donde el montaje es a la vez una operación creadora de formas y promotora de conceptos. Por esos modestos medios, Val del Omar durante los recónditos años del PLAT se contacta con una de las matrices fundantes que, desde los tiempos de las vanguardias históricas, han hechizado al cine: el collage plástico a partir de elementos hallados. Pero lo hace interviniendo con sus imágenes y palabras en una dirección que reniega de la división entre búsqueda poética e indagación conceptual: para este utopista del cine, el montaje era una operación tan crucial que operaba como hilo conductor entre sus distintas áreas de trabajo, aún cuando en tiempos en que los recursos materiales estuvieran reducidos al mínimo.
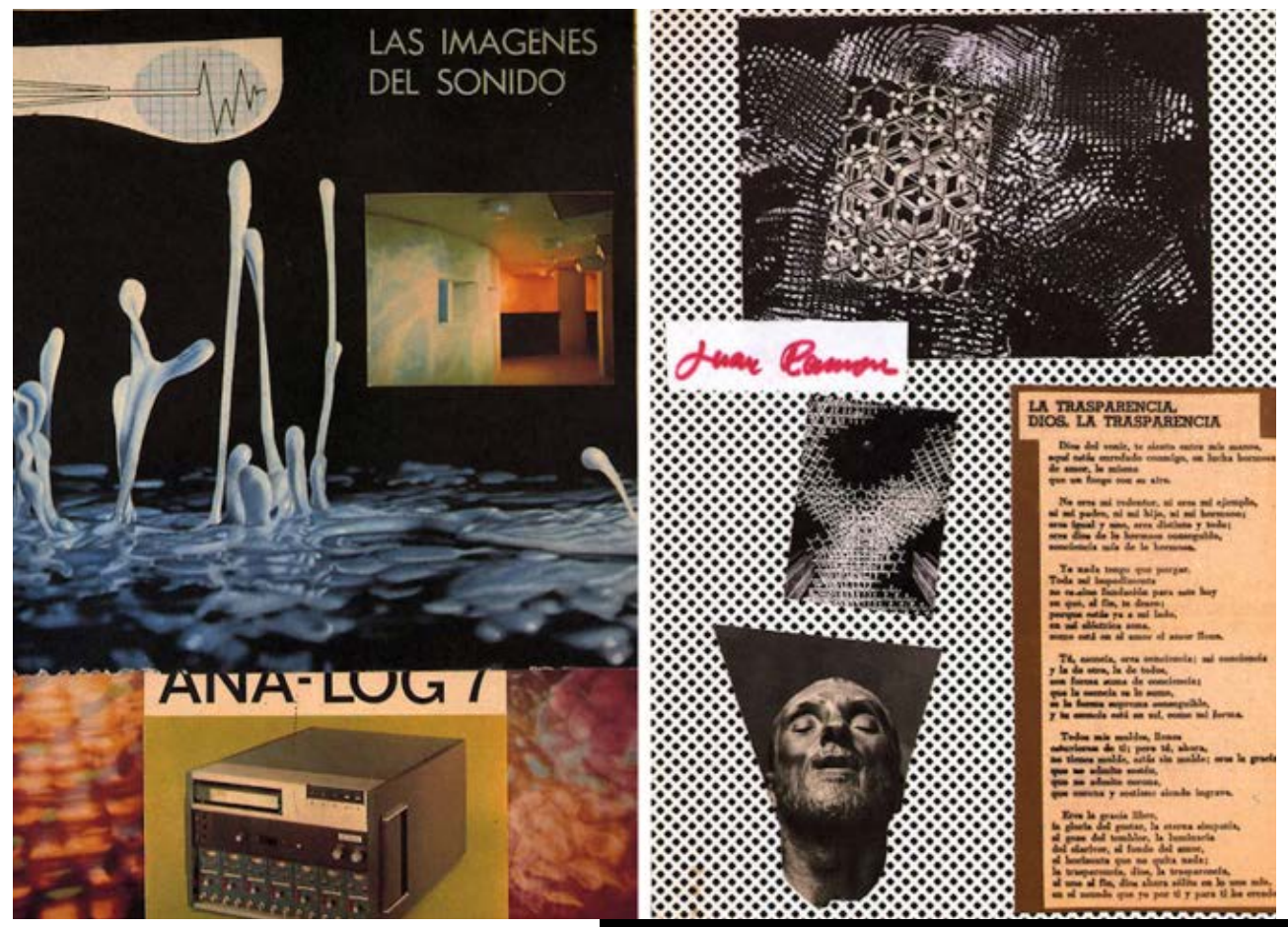


\section{EXPANDIR EL MONTAJE, REINVENTAR UNA EXPERIENCIA}

Val del Omar fue, durante la mayor parte de su larga carrera, un inventor independiente. $Y$ en el último tramo de su recorrido, fue un inventor de catacumbas. Durante pocos años, a inicios de los años sesenta, contó con un laboratorio en la Escuela Oficial de Cine (EOC), sostenido por el Estado español. Pero esas instalaciones fueron desmontadas a mediados de esa década, y el realizador, inventor y poeta prosiguió sus investigaciones en otro laboratorio literalmente subterráneo, al que bautizó PLAT (Picto-Lumínico-Audio-Táctil). En ese ámbito, localizado en un subsuelo, prosiguió explorando distintas imágenes técnicas, soportes y dispositivos, prestando especial atención a las ventajas ofrecidas por el ultraliviano super-8, sistema en auge durante aquella década, y las emergentes promesas de la holografía láser, entre otras. Sobre Variaciones sobre una granada (ca. 1979) [Figura 4] destaca Manuel Tranche (2012):

Las fotografías del rodaje conservadas muestran cómo VDO se aleja con esta película de la simple captación del motivo, para evolucionar hacia una imagen generada en capas, producto de la confluencia de diversos mecanismos simultáneos. En este caso, espejos planos y cóncavos, dispositivos de truca, focos de luz puntual, técnicas de filmación fotograma a fotograma... En definitiva, un método de rodaje donde el montaje se subsume en parte y la noción del tiempo y el movimiento se alejan definitivamente de la convención al uso (pp. 15-16).

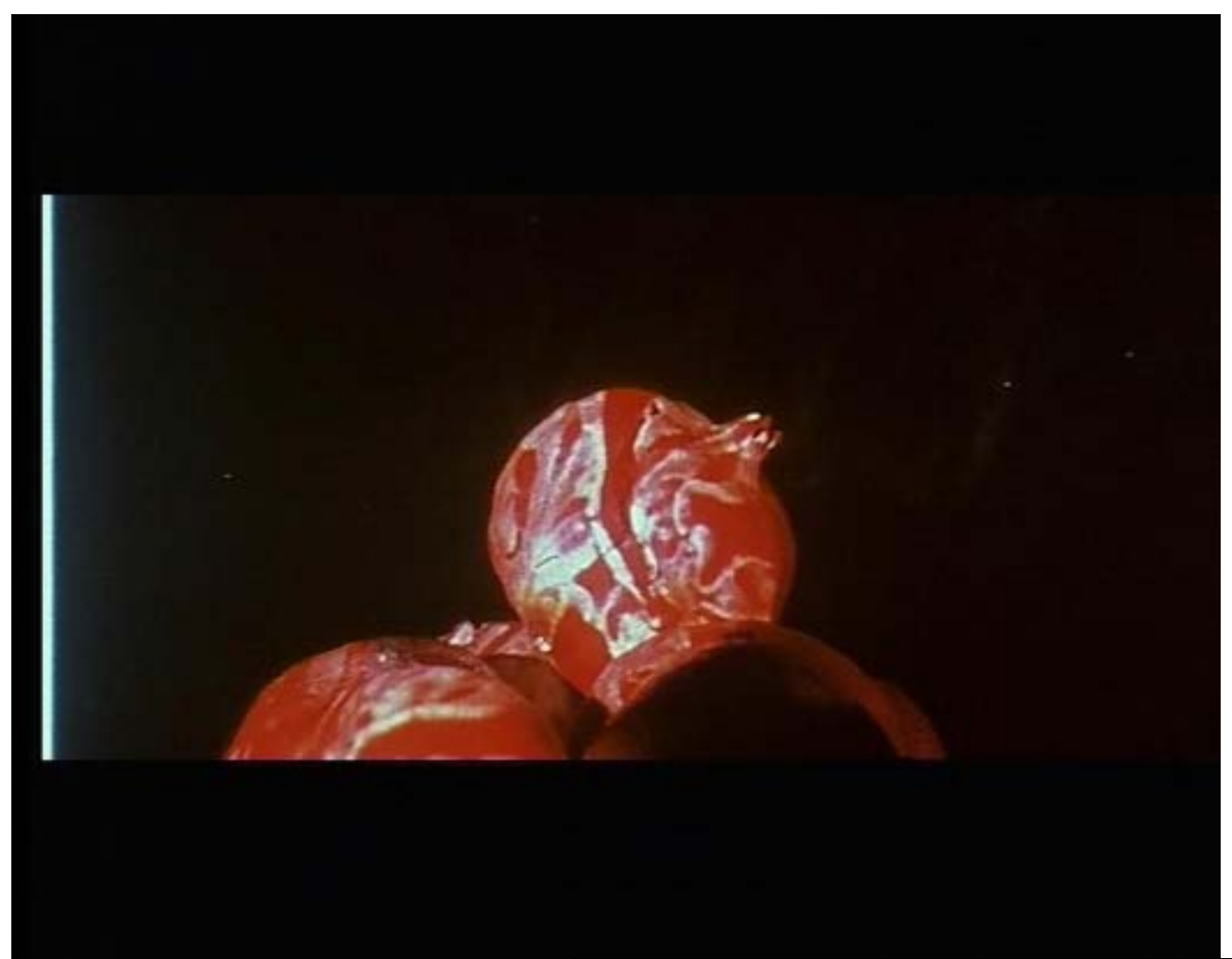


Podríamos definir a ese complejo artefacto que Val del Omar llamaba simplemente su Truca como un complejo aparato productor de operaciones de montaje multimedial, que integraba recursos fotográficos, fílmicos, videográficos y de emisiones láser, montando a otra escala, entre uno y otro medio. Conservando un término frecuente para designar a las copiadoras ópticas, la Truca ponía en juego al montaje mediante una compleja instalación multisoportes, entre distintos medios y estados de la imagen. En el breve fragmento conservado de sus Variaciones sobre una granada el montaje no solamente interviene en el interior del mismo cuadro, sino que se potencia al proyectar imágenes sobre una granada como pantalla, al recorrerla con los haces láser o al convocar a un conjunto de diversas imágenes técnicas para extraer desde su interjuego la posibilidad de ejecutar una dinámica de análisis y síntesis, o aún mejor, una trasmutación de ese fruto emblemático por medio de la acción de un cine en estado de invención. La Truca era así una máquina cinemística por excelencia, orientada desde las operaciones de (y en) las imágenes, hacia una metamorfosis. Y por medio de ella, el autor buscaba la transformación de la actividad espectatorial en una aventura de la experiencia audiovisual, integrando goce estético y conocimiento. La obra de Val del Omar revela las múltiples dimensiones de un montaje conceptual que atraviesa el cine, el video, la televisión y otras técnicas de imagen y sonido. Se abre, por medio del montaje, hacia distintas tecnologías y formas artísticas, transformándolas, revelando su posición central en el lenguaje poético del cine y a la vez la hibridación que le es constitutiva.

\section{REFERENCIAS}

Beard, T. (2010). José Val del Omar a lo largo de tres vanguardias. En AA.VV., Desbordamiento Val del Omar (pp. 56-65). Madrid, España: Museo Nacional Centro de Arte Reina Sofia.

Bonet, E. (2016). Escritos de vista y oido. Barcelona, España: MACBA.

Brenez, N. (2010). Técnica, teofanía, método: José Val del Omar y la vanguardia francesa. En AA.W. Desbordamiento de Val del Omar (pp. 45-52). Madrid, España: Museo Nacional Centro de Arte Reina Sofía.

Codesal, J. (2015). Soy tu impotencia. Sobre la recuperación de Acariño galaico (De Barro). En E. Duque (Ed.), Val del Omar. Más allá de la órbita terrestre (pp. 213-220). Ciudad Autónoma de Buenos Aires, Argentina: BAFICl.

De Lucas, G. y Pintor Iranzo, I. (2017). Poética del montaje en Aguaespejo Granadino. Investigación estética, técnica y pedagógica sobre la experiencia del espectador en la obra de José Val del Omar. L'Atalante. Revista de Estudios Cinematográficos, (24), 165-184. Recuperado de http: / Www.revistaatalante.com/index.php?journal=atalante\&page=article\&op=view\&path\%5B\%5D=466

Fernández Cuenca, C. [1965] (2015). Investigaciones y experiencias. En E. Duque (Ed.), Val del Omar. Más allá de la órbita terrestre (pp. 125-132). Ciudad Autónoma de Buenos Aires, Argentina: BAFICl.

Godard, J-L. (1956). Montage, mon bon souci [Montaje, mi gran inquietud] . Cahiers du cinéma, (65). 30-31.

Jurgenson, A. (1995). La práctica del montaje. Barcelona, España: Gedisa.

Tranche, M. (2012). Panóptico Val del Omar. De la pantalla al palimpsesto. Archivos de la Filmoteca, (69) 121-133 
Val del Omar, J. (Productor y director). (1934). Fiestas cristianas/Fiestas profanas [Película]. España: Archivo María José Val del Omar y Gonzalo Sáenz de Buruaga.

Val del Omar, J. (Productor y director). (1953-1955). Aguaespejo granadino [Película]. España: Filmoteca de Andalucia.

Val del Omar, J. (Productory director). (1958-1960). Fuego en Castilla (Tactilvisión del páramo del espanto) [Película]. España: Filmoteca de Andalucia.

Val del Omar, J. (Productor y director). (1961-1995). Acariño Galaico (de Barro) [Película]. España Filmoteca de Andalucia.

Val del Omar, J. (Productor y director). (ca. 1979). Variaciones sobre una granada [Película]. España: Archivo María José Val del Omar y Gonzalo Sáenz de Buruaga.

Val del Omar, J. (2010). Escritos de poética, técnica y mistica. Madrid, España: Ediciones de La Central. MNCARS, Universidad de Navarra.

Val del Omar, J. (2012). Tientos de erótica celeste. Granada, España: Diputación de Granada.

Villegas López, M. [1962] (2015). Val del Omar, poeta del cine. En E. Duque (Ed.), Val del Omar. Más allá de la órbita terrestre (pp. 151-155). Ciudad Autónoma de Buenos Aires, Argentina: BAFICI. 